\title{
The Teaching Excellence Framework (TEF): yet more competition - and on the wrong things!
}

\author{
Phil Race
}

When the UK Green Paper which heralded the TEF was released in 2015, it claimed that the aim was to introduce something much less burdensome than the Research Excellence Framework (REF). Working in higher education institutions (HEIs) as a consultant, I see that the 'less burdensome' intention is already clearly failing, with the energy of staff at all levels being sapped by numerous planning and strategy meetings as institutions gear themselves up for the inevitable competition and league-table fallout which will accompany the TEF.

Participating as a National Teaching Fellow in the various consultations preceding the present Higher Education bill, it was clear that there were problems with the three words involved in TEF. What are the best metrics to try to quantify 'teaching'? In particular, what on earth might 'excellence' in teaching be, and how could this possibly be measured in a valid or reliable way? And even the word 'framework' implies a concept so complex that it could hardly be expected to be fair or productive.

So how can we enhance the student experience of higher education? Higher education institutions and practices tend to change very slowly. Einstein is reputed to have said 'it is sheer madness to keep doing the same thing, and to expect different results'. Therefore, if we want different and better results, we need to be doing different things, not just continuing to put the same old ways of doing things under spotlights, focusing on a few selected dimensions. Overburdened staff in HEls are already burning themselves out, using traditional methods of assessment and feedback introduced long ago when student numbers were much smaller. Indeed, assessment and feedback take up far more time and energy than 'teaching' per se and additional TEF burdens may thus be a step too far.

There are numerous ways to try to teach well. Any attempt to highlight particular aspects of good teaching will exclude other equally worthy ways of giving students a good higher education experience. But perhaps the biggest problem is with the word 'excellence'. Rewarding excellence breeds competition and the losers, who will always be far more numerous than the winners, may well be disappointed and discouraged - and therefore less likely to try again to 


\section{TEF Special Edition}

excel. Most of the benefits of collaboration may be lost when individuals, departments and institutions are made to compete.

It would be much wiser to redirect the energy currently being expended on TEF to reviewing the processes of assessment and feedback. Successful educational outcomes, including the now oft-cited 'longitudinal' ones, depend very strongly on the quality of the assessment and of the consequent feedback that students experience, (e.g. HEA, 2012). The higher education sector still over-uses some processes, including the much-criticised unseen written exams (which often continue to measure what is remembered rather than what is learned), and coursework essays (despite all the research which shows that we are poor as a sector at grading them fairly or reliably, and despite ever-increasing concerns about who actually wrote them). Essays remain a good way to get formative feedback to students on their thinking and writing, but assessing them fairly is fraught with difficulty.

Even though the National Student Survey, which feeds in to the TEF, has been adjusted for 2017 onwards and includes issues relating to the student experience of assessment and feedback, known as an aspect which students themselves find the least satisfactory, I would nevertheless argue that the TEF would do better to focus more on assessment rather than teaching. So, in short, the TEF seems set to measure the wrong things and to generate greater competition in a world which instead needs much more emphasis on collaboration. Rather than vain attempts to continue to do the same old things better, processes are needed to recognise and reward outstanding assessment and feedback practice, which itself needs to be better monitored, developed and changed to keep up with the present and future needs of our students, and of the world beyond HEls.

\section{Reference list}

Higher Education Academy (2012) A Marked Improvement: transforming assessment in higher education. York: Higher Education Academy. Available at: https://www.heacademy.ac.uk/resource/marked-improvement-transforming-assessment-highereducation-assessment-review-tool (Accessed: 03 April 2017). 